\title{
Math-Related Difficulties in Thematic Map Use in Lower Secondary Education
}

\author{
Martin HANUS 1 \\ Charles University, Prague, CZECHIA \\ Kateřina ŠVUBOVÁ ${ }^{3}$ \\ Charles University, Prague, CZECHIA
}

Lenka HAVELKOVÁ 2

Charles University, Prague, CZECHIA

${ }^{1}$ Corresponding author: Assist. Prof.; Charles University, Faculty of Science, Department of Social Geography and Regional Development, Centre for Geographical and Environmental Education, Albertov 6, 128 00, Prague 2, CZECHIA. martin.hanus[at]natur.cuni.cz. ORCID: 0000-0002-9873-5106

${ }^{2}$ Assist. Prof.; Charles University, Faculty of Science, Department of Social Geography and Regional Development, Centre for Geographical and Environmental Education, Albertov 6, 128 00, Prague 2, CZECHIA. l.havelkova[at]natur.cuni.cz. ORCID: 0000-0002-6266-4801

3 Master graduate; Charles University, Faculty of Science, Department of Social Geography and Regional Development, Centre for Geographical and Environmental Education, Albertov 6, 128 00, Prague 2, CZECHIA. svubova.katerina[at]gmail.com. ORCID: 0000-00034804-2675

\section{Abstract}

The use of maps as a complex source of geographical information requires a certain level of mathematical literacy. The lack of such literacy can cause severe failures in map use and the development of map skills. Therefore, this paper aims to contribute to the discussion about the difficulties in using quantitative thematic maps (specifically choropleth maps and proportional symbol maps), which may result from insufficient level of mathematical literacy at the lower secondary level of education. The paper is structured into two studies: Study 1 focuses on the continuity of mathematics and geography curricula (employing methods of expert cognitive walkthrough and content analysis), while Study 2 examines the relationship between achieved mathematical literacy and map skills (using two achievements tests and a questionnaire). The findings show that the continuity of curricula often fails and that map skills development precedes the development of mathematical literacy. The identified inappropriate chronology might have important consequences, since the correlation of mathematical literacy with the level of thematic map use skills proves to be statistically significant. Their relationship is significant in all aspects of map use (map reading, analysis, and interpretation) and in the use of both types of quantitative thematic maps examined in the study. The results should be of interest to geography teachers, teacher trainers, and curriculum leaders on the national and school levels.

\section{Keywords}

Geography Education; Map Skills; Thematic Map; Mathematical Literacy; Lower Secondary Curriculum 
We live in a visual age that prefers visual forms of information presentation, such as diagrams, photos, figures, and maps (LaSpina, 1998). In cartography, this is reflected in the increasing importance of thematic maps, which can portray various statistical phenomena in a clearer, better-arranged manner than a table or graph can - provided, obviously, that they are understood by the user (Schaab, Adams, \& Coetzee, 2020). Considering the fact that maps are an essential tool for the development of geographical thinking (Hanus \& Havelková, 2019), map skills should be fostered in students during geography lessons.

Importantly, skills related to map use require good mathematical literacy (Havelková \& Hanus, 2019; Wiegand, 2006). The lack of such literacy can be the main impediment to successful development of map skills. The relationship between mathematical and map skills has been examined in several studies (Cheek \& Muir, 1986; Dorn et al., 2005; Grofelnik \& Pap, 2013; Ishikawa, 2016; Rasmussen \& Winsløw, 2013; Wiegand, 2006). However, most of these consider the most important mathematical skill to be spatial imagination and the most important map skill to be map reading and/or wayfinding. These studies also often focus on topographic maps. In contrast to topographic maps, thematic maps (and a whole range of associated mathematical operations and required map skills) are encountered more frequently by individuals in everyday life; they often do not respect basic cartographic and design principles and thus might easily be misinterpreted (Schaab, Adams, \& Coetzee, 2020). However, the studies rarely address thematic maps. Given the results of previous studies pointing out the insufficient level of students' thematic map use skills - specifically higher-level skills (Havelková \& Hanus, 2018; Korycka-Skorupa \& Gołębiowska, 2020; van Dijk, van der Schee, Trimp, \& van der Zijpp, 1994) - it is necessary to consider the influence of students' mathematical literacy together with the potential independent variables that are traditionally investigated (e.g., gender, liking for geography, school type), which have been shown to have ambiguous influence in some cases (Havelková \& Hanus, 2019).

This paper contributes to the discussion about difficulties in the use of thematic maps that result from insufficient level of mathematical literacy. This is examined at two curriculum levels - the project curriculum and the achieved curriculum - with the following specific aims:

1) To identify the mathematical operations needed for the successful performance of most common map skills, considering the cognitive level (i.e., map reading, analysis, interpretation, and design), and, subsequently, to analyse national and school curricula together with mathematics textbooks to identify possible obstacles to the continuity of development of mathematical literacy and map skills at the lower secondary educational level in Czechia (see Study 1)

2) To verify the relationship between achieved mathematical literacy and map skills among lower secondary students and to verify if students' level of map skills is significantly influenced by any other independent variable, namely age, gender, school type, and grades in and liking for geography and mathematics (see Study 2)

Given these two interrelated aims that enable us to evaluate the influence of math literacy on map skills, the paper is divided into two studies with a common 
Theoretical Framework and Discussion, but with separate Methodology and Findings sections. The first study primarily employs analysis using aspects of expert cognitive walkthrough to identify mathematical operations needed to use thematic maps in combination with content analysis of the curricula, while the second study builds on empirical research using a thematic map use test along with a mathematics test and a questionnaire.

The combined results of these studies could be of importance to teachers when planning and implementing map skills development in their classes, to teacher trainers when compiling a list of compulsory courses and designing content for preservice geography teachers, and to curriculum designers at the national or school level.

\section{Theoretical Framework}

\section{Map Use}

Using a map as a geography-specific source of information is one of the essential components of teaching geography. However, map use is comprised of a highly variable set of operations, not only from the cognitive perspective. As Kwan (1994) states, map work consists of a knowledge component (understanding map concepts) and a performance component (map skills). Map skills, then, vary depending on whether the individual is reading, analysing, interpreting, or designing a map (for a detailed definition of these types of map skills, see Wiegand, 2006). From reading to interpretation and to design, the complexity and cognitive difficulty of the skills increase (Hanus \& Marada, 2014; Wiegand, 2006), as demonstrated by Hanus and Havelková (2019) in their diagram of map use in education (Figure 1). The general presumption of this increasing complexity is that sufficient mastery of lower-level skills is a prerequisite for higher-level (that is, more complex) skills. However, these four general types of map skills can be further divided into specific operations with maps (see Figure 1).

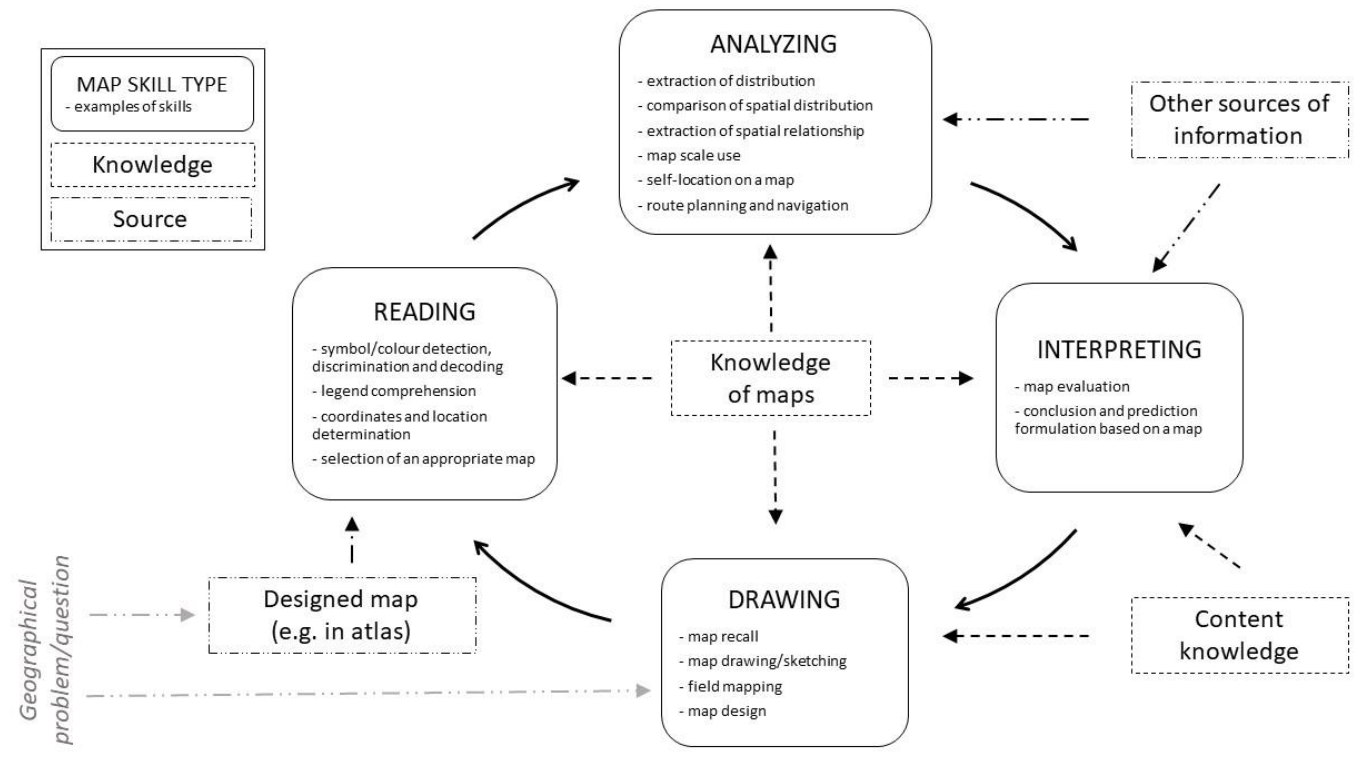

Figure 1. Map use in the education process (Hanus \& Havelková, 2019) 
The chronological arrangement of the development of map use at the lower secondary level in Czech schools can be derived from a study by Hanus and Marada (2013), which uses content analysis of the curriculum with respect to the development of map skills, as well as from the conclusions made by Hanus and Havelková (2019). It is evident that most geography teachers follow the traditional arrangement of map use development, where block teaching of the cartography unit is inserted at the introduction of geography courses (in Grade 6, with students aged 12 years old on average), within which students become acquainted with the concept of maps and acquire the essential map skills. This introductory block teaching is then followed by regular map work during the teaching of other thematic units (Hanus \& Havelková, 2019).

When investigating students' map skills, it is necessary to be aware not only of their diverse complexity, but also of the high variability of maps that can be used. Different types of maps require different mathematical operations and map skills. Considering the aims of this paper, we decided to focus only on quantitative thematic maps - that is, thematic maps depicting quantitative data - as these require the most mathematical skills to use due to the nature of the data and mapping methods employed. For this reason, we focused specifically on choropleth and proportional symbol mapping, which are the most commonly used mapping methods to depict quantitative data on thematic maps in Czech school atlases intended for secondary geography education (Havelková \& Hanus, 2018). It is worth noting that the frequency of choropleth maps in school atlases is approximately two times higher than that of proportional symbol maps, and other mapping methods for quantitative data depiction are scarcely used.

Proportional symbol maps use symbols (e.g., circles, bars, spheres) that vary in size in order to represent a quantitative variable. The relationship between a represented value and the symbol size should be mathematically defined - that is, expressible by a function - and appropriately depicted in the map legend. Proportional symbol maps can express the structure of the variable as well - for example, by using a structured pie chart where the absolute value of an individual variable category can be determined based on the size of the pie slice and the pie chart as a whole. While proportional symbol maps commonly visualize absolute data, choropleth maps are only suitable for relative data. Choropleth maps illustrate the value of a variable with colour or patterns within a predefined geographic area. The value is often related to the area of the chosen territorial unit or its number of inhabitants (Slocum, McMaster, Kessler, \& Howard, 2013).

\section{Mathematical Literacy}

Mathematical literacy generally refers to an individual's capacity for the study and application of mathematics. This includes the cognitive and executive components responsible for performing mathematical operations, from simple calculations to complex mathematical judgments (Jablonka, 2003).

The Organisation for Economic Co-operation and Development (OECD, 2003) defines mathematical literacy as the capacity to identify, understand, and engage in mathematics and make well-founded judgements about the role that mathematics plays, as needed for an individual's current and future life, occupational life, social 
life with peers and relatives, and life as a constructive, concerned, and reflective citizen.

According to the Czech Research Institute of Education (2011), mathematical literacy can be divided into three components: situations and contexts, competences, and mathematical content. The situations and contexts component involves the ability to use acquired knowledge and skills and apply them to real situations, whether in mathematics, other subjects, or life outside of school. The competences component is applied by students in problem solving and can be divided into seven areas: mathematical thinking, argumentation, modelling, communication, the definition and solving of problems, the use of mathematical language, and the use of tools. The third component, mathematical content, encompasses the structures and concepts required to formulate and solve mathematical problems; it thus involves specific knowledge.

In the Czech lower secondary curriculum (Research Institute of Education, 2007), the educational area of Mathematics and Its Application lacks explicit emphasis on the development of the situation and contexts component, as it is developed only within the topic of Non-standard Application Tasks and Problems. However, the development of this component is essential for other educational areas where mathematical literacy is applied in a different (that is, not purely mathematical) context.

\section{Relationship between Map Use and Mathematical Literacy}

Rasmussen and Winsløw (2013) derive the closeness of mathematics and geography from the etymology of their names - geography and geometry. The close relationship specifically between mathematics and map skills suggests the division of map operations into map numeracy and map literacy that is proposed by Wiegand (2006). Map numeracy refers to the mathematical knowledge and skills that a map user must master in order to successfully work with a map; it includes, for example, the estimation and measurement of distance, the determination and use of map scale, and the understanding of grids and coordinates. Muir and Cheek (1986) also mention that the understanding of the bird's-eye view of maps is similar to that used in Euclidean geometry or that used for the perception of directions. Many studies (e.g., Anthamatten, Bryant, Ferrucci, Jennings, \& Theobald, 2018; Ishikawa, 2016; Jadallah et al., 2017; Liben, Myers, Christensen, \& Bower, 2013) point to a connection between map work and the spatial imagination developed in mathematics, where a map can be seen as a suitable and illustrative tool for developing this imagination as well as the skill to translate a 3D reality into a 2D space (Uttal, 2000). Similarly, a map may help with understanding mathematical functions, statistical methods, and their practical use (Rasmussen \& Winsløw, 2013).

Map numeracy is also used in determining geographical location: the geographical coordinate grid is essentially just a four-quadrant Cartesian coordinate system. In this respect, Muir and Cheek (1986) draw attention to the lack of coordination between geography and mathematics within the curriculum, since the four-quadrant geographical coordinate grid is presented to students in geography lessons earlier than in mathematics, where they had only encountered a singlequadrant system to that point. Wiegand (2006), however, points out that coordinate 
grids are often intuitively understood by students even before they first encounter them in geometry or when plotting function graphs. Moreover, Anthamatten et al. (2018) remark that introducing the four-quadrant coordinate system to students for the first time on a map may be more natural and easier to understand than if introduced in mathematics. Indeed, the use of these systems in geography could precede their teaching in mathematics. Nevertheless, this reverse chronology must be intentional, and mathematics and geography teachers should cooperate for students to achieve the needed outcomes in both subjects.

Theoretical work and empirical studies of mathematics and map work both show a link between map skills and mathematics. This relationship has been proven by improved results in map skill tests among students from math and science tracks (Grofelnik \& Pap, 2013), improved results in mathematics or spatial imagination after completing a special combined course (Anthamatten et al., 2018; Dorn et al., 2005; Jadallah et al., 2017), by the comparison of the results of two parts of testing - mathematical or spatial imagination, and map-focused (Ishikawa, 2016; Liben et al., 2013), or by the positive dependence of math grades and the level of some map skills or work with some types of maps (Havelková \& Hanus, 2018; van Dijk et al., 1994).

Thus, the interdependence and interconnectedness of map numeracy and map literacy - the geography and the mathematics - is more than evident; a higher level of proficiency in one area helps to develop the other. Rasmussen and Winsløw (2013) therefore propose the idea of integrating these two areas in lower secondary lessons. Integration of geography and mathematics in map skills development would result in higher teaching efficiency and the associated time savings - when teaching map work, it would not be necessary to repeatedly develop (or recall) the necessary mathematical literacy. Additionally, students would perceive mathematics as being less abstract and impractical as a result of being able to apply mathematic knowledge and skills more frequently in real-life situations (Whittle, 2007).

The above-mentioned theoretical and empirical studies form the fundamental theoretical framework for the two studies presented, which, unlike many previous studies, do not focus on topographic maps and spatial orientation, but rather on quantitative thematic maps and mathematical literacy in a broader sense.

\section{Study 1: Mathematical Literacy and Map Skills in Czech Curricula}

Methodology. In line with the first aim, this study was carried out using a combination of methods. First, a deep analysis of the process of map work with aspects of cognitive walkthrough procedure (Polson, Lewis, Rieman, \& Wharton, 1992) was employed to identify mathematical operations needed for map work in general, and subsequently for work with thematic maps - choropleth and proportional symbol maps in particular.

Second, a content analysis of curricula was performed, specifically focusing on the section dealing with the curriculum and students' expected outcomes in mathematics, in order to identify the chronology within which all the necessary mathematical operations are taught at Czech lower secondary schools (students 
commonly aged 11-15). Considering the two-level curriculum in Czechia (the national and school levels), the Framework Education Programme for Elementary Education (the national compulsory curriculum) and selected School Education Programmes were analysed. As the Czech education system gives schools a relatively large amount of freedom in the teaching plan at individual levels of education, there are certain differences among schools. Nevertheless, most schools follow the traditional curriculum structure, meaning that differences in teaching timelines are quite minor (Janík, Maňák, Knecht, \& Němec, 2010). Thus, for the analysis of school curricula, five schools (i.e., five School Education Programmes) were chosen; they differ both in the size of the city in which they are located (ranging from schools in the capital or a regional city to rural schools) and in the size of the school itself (ranging from large schools with multiple classes per grade to schools with fewer students but at least one class per grade). All selected schools are general schools with no strict specialisation to one or more fields or tracks. Three schools are general elementary schools and two schools are lower grades of grammar schools (for more gifted students who are being prepared for future university studies), though both types of schools have to follow the same lower secondary national curriculum - including the same regulations regarding the number of geography lessons a week.

In ambiguous cases, curriculum analysis was supplemented with content analysis of mathematics textbooks to identify the chronology of teaching mathematics at the lower secondary level. The whole set of the most commonly used mathematics textbooks in Czech lower-secondary schools (see, for example, Rendl et al., 2013) was included in the analysis - twelve textbooks in total. Specifically, the grades in which the given mathematical operations are generally developed were identified based on the textbooks' content.

Map work in the curriculum. The Framework Education Programme for Elementary Education, the national compulsory curriculum, is a binding document that nevertheless formulates educational outcomes relatively generally and leaves considerable freedom and responsibility for individual schools regarding the compilation of their school curriculum - for example, educational outcomes are not set for individual grades but only for entire levels of education. The school curricula can vary considerably among schools, but, in practice, most schools adhere to the same traditional curriculum structure (see below), as the content analysis of the selected School Education Programmes confirmed.

The national geography curriculum requires lower secondary students to use maps as a source of information. Specifically, they are asked to evaluate and interpret information in maps (that is, read and analyse them as well) and create or draw plans and sketch maps; complex map design in a cartographic meaning is not required. Although it is not strictly prescribed in the national curriculum, lowersecondary map work is traditionally developed in the block teaching of cartography, commonly in Grade 6 (students aged 12). The focus is on both the knowledge and understanding of map-related concepts and map skills (Hanus \& Havelková, 2019), and the lessons consider different types of maps, especially general reference maps, topographic maps, and the most common thematic maps, including choropleth maps and proportional symbol maps. The knowledge and skills developed in cartography 
are then used to teach other geographical issues of human, physical, or regional geography (Research Institute of Education, 2007). The national curriculum does not mention which specific types of maps students should learn to work with. However, the geographical curriculum does require the use of statistical data and their visualization, and choropleth and proportional symbol maps are the most frequently used methods of statistical data visualization in maps in lower secondary geography textbooks and school atlases. Therefore, for the effective development of map work, it is crucial to be aware of the mathematical background of maps and especially the mathematical operations needed to use them.

Mathematical operations needed for map use. Considering the cognitive variability of individual types of map skills, the mathematical operations identified through the expert cognitive walkthrough as necessary for effective map use are structured according to the model in Figure 1. It is important to keep in mind the increasing complexity of individual map skill types, which is reflected in the increasing requirements for performing mathematical operations; for example, since map analysis also requires map reading skills, it also uses the mathematical operations specifically required for reading a map. However, not all of the mathematical operations listed below are applied each time students use or design a map, since there are a variety of possible operations using a map and there exists a broad range of maps. The aim of the cognitive walkthrough was to consider this variability and cover all mathematical operations that students need when they are working with a map. For example, some of the listed mathematical operations can be necessary when students compare the spatial distribution of the largest world cities and the countries with the highest population density, while others are necessary to measuring how the built-up area in their hometown has increased during the last decade.

Map reading. Map reading is the least cognitively demanding; the user acquires necessary information, works with the legend, and locates objects. Working with the coordinate grid and determining positions are in the domain of mostly topographic maps, but the skills of detecting, distinguishing, and decoding symbols and colours, as well as legend comprehension, are applied when working with all types of maps, including quantitative thematic maps. Therefore, below is a list of the identified mathematical operations necessary to fully develop each of the above operations with thematic maps.

Symbol and colour detection, distinction, and decoding. Distinction of geometric shapes and patterns, relative relationships and positions of planar formations (points, lines, and planes), spatial imagination

Legend comprehension. Numerical axis, direct and inverse proportionality, squares and roots, functions, relative and absolute data, percentages and intervals, spatial imagination

Map analysis. The ability to analyse a map builds on the ability to read it; without proper reading, the map cannot be analysed. The information read is thus used to extract and compare spatial distribution and spatial relationships, and to work with the map scale. 
Extraction of spatial distribution. geometrical relationships between objects in space, distances and measurements, frequencies of occurrence of objects and phenomena, relative and absolute data, ratios and proportions, spatial imagination

Comparison of spatial distribution. Frequencies of occurrence of objects and phenomena (comparison, evaluation, calculation of subsequent variables, etc.), relative and absolute data, ratios and proportions, sets and subsets, spatial imagination

Extraction of spatial relationship. Dependencies and relationships, direct and inverse proportionality, sets and subsets, arrangement and hierarchisation

Map scale use. Proportions (fractions, cross-multiplication), distances, length measurements, unit conversions (length and area)

The other two constituent skills of map analysis mentioned by Hanus and Havelková (2019) - locating oneself on the map and route planning (i.e., navigation) - are specifically the domain of topographic maps and, as such, will not be discussed here.

Map interpretation. As part of the interpretation of the map, the user performs map evaluation and, above all, the formulation of conclusions and predictions. Both of these map skills are highly specific to individual map types and to the concrete problems that are being addressed. The successful realisation of these skills requires knowledge and understanding of the characteristics of the mapping method used - in the context of this paper, choropleth and proportional symbol mapping. Mathematical operations needed for interpretation are thus determined primarily by this knowledge (for the list of specific mathematical operations, see the Knowledge of maps section below) and by mastering the operations required for reading and analysing the map.

Map design. The process of designing a (thematic) map differs from the other types of map skills and thus also requires its own specific mathematical operations. The most important mathematical skills for collecting, preparing, and categorising data for designing a quantitative thematic map are statistical skills. The process of creating the thematic map itself is more of a practical task, which nowadays takes place more and more frequently on a computer.

Data collection and preparation. Statistical data processing (calculating the mean, mode, median, and linear arrangement of values), working with tables, number sequences, quantitative sorting, histograms, percentages, intervals

Map design. Geometry (practical work with ruler, protractor, and compass in the case of manual map drawing)

Knowledge of maps. The basis of successful map work is always formed by understanding fundamental map concepts (e.g., projection, scale, and symbolic representation). As the map skills increase in complexity, the level of map knowledge required - both qualitative and quantitative - increases as well. If the student does not understand the essence of the map (that is, what it expresses and what it does not), they cannot draw any conclusions from it. However, the mathematical skills required for this understanding are dependent on the specific 
symbolic representation used - that is, the mapping method in case of thematic maps, and whether the method is quantitative or qualitative.

- Quantitative thematic maps: continuous and discrete phenomena, arrangement and hierarchisation, frequencies, relative positions of planar formations, absolute and relative data, ratios and percentages, fractions, intervals, arithmetic mean, mathematical functions

- Qualitative thematic maps: continuous and discrete phenomena, arrangement and hierarchisation, directions and vectors, direct and inverse proportionality, length and area

However, the above list of identified mathematical operations can vary based on the problem that is being solved. With regard to Study 2's focus on choropleth and proportional symbol maps, Table 1 lists the specific mathematical operations that may need to be applied when working with these maps. The list also considers the type of map skills required by the Czech lower secondary geography curriculum.

Table 1

List of the mathematical operations needed for the use of choropleth and proportional symbol maps identified based on the expert cognitive walkthrough

\begin{tabular}{|c|c|c|c|}
\hline Map work & Map skill & Choropleth map & $\begin{array}{l}\text { Proportional } \\
\text { map }\end{array}$ \\
\hline \multirow{4}{*}{ 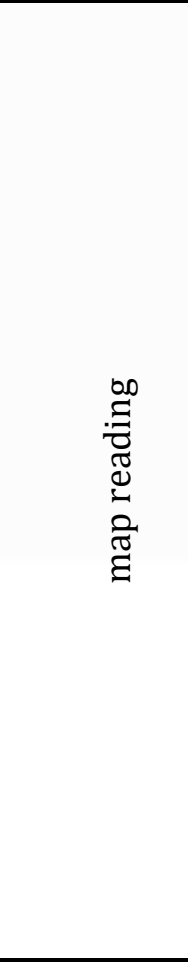 } & $\begin{array}{l}\text { Symbol and colour } \\
\text { detection and } \\
\text { distinction }\end{array}$ & $\begin{array}{l}\text { Planar formations and } \\
\text { their relative position, } \\
\text { distinguishing } \\
\text { geometric shapes and } \\
\text { patterns (grid), spatial } \\
\text { imagination, comparing } \\
\text { values }\end{array}$ & $\begin{array}{l}\text { Planar and spatial } \\
\text { formations and their } \\
\text { relative position, } \\
\text { spatial imagination, } \\
\text { comparing values, } \\
\text { comparing areas and } \\
\text { volumes }\end{array}$ \\
\hline & $\begin{array}{l}\text { Legend } \\
\text { comprehension }\end{array}$ & $\begin{array}{l}\text { Intervals, percentages, } \\
\text { fractions, relative data, } \\
\text { numerical axis, } \\
\text { exponentiation }\end{array}$ & $\begin{array}{l}\text { Working with } \\
\text { diagrams, percentages, } \\
\text { ratios, and functions }\end{array}$ \\
\hline & Symbol decoding & $\begin{array}{l}\text { Intervals, percentages, } \\
\text { direct proportionality, } \\
\text { frequency, comparing } \\
\text { values }\end{array}$ & $\begin{array}{l}\text { Working with } \\
\text { diagrams, percentages, } \\
\text { intervals, } \\
\text { proportionality, } \\
\text { comparing values, } \\
\text { comparing fractions }\end{array}$ \\
\hline & $\begin{array}{l}\text { Identification of } \\
\text { cardinal and } \\
\text { intercardinal } \\
\text { directions } \\
\end{array}$ & $\begin{array}{l}\text { Spatial imagination, } \\
\text { working with the } \\
\text { coordinate grid }\end{array}$ & $\begin{array}{l}\text { Spatial imagination, } \\
\text { working with the } \\
\text { coordinate grid }\end{array}$ \\
\hline 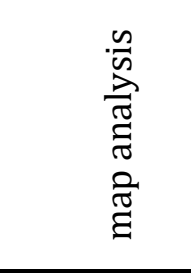 & $\begin{array}{l}\text { Extraction of spatial } \\
\text { distribution }\end{array}$ & $\begin{array}{l}\text { Spatial imagination, } \\
\text { planar formations and } \\
\text { their relative position, } \\
\text { comparing values }\end{array}$ & $\begin{array}{l}\text { Spatial imagination, } \\
\text { planar/spatial } \\
\text { formations and their } \\
\text { relative position, } \\
\text { comparing areas and } \\
\text { volumes }\end{array}$ \\
\hline
\end{tabular}


Hanus, M..; Havelková, L., Švubová, K. (2021). Math-Related Difficulties in Thematic Map Use...

\begin{tabular}{|c|c|c|c|}
\hline & $\begin{array}{l}\text { Extraction of spatial } \\
\text { relationship }\end{array}$ & $\begin{array}{l}\text { Spatial imagination, } \\
\text { intervals, percentages, } \\
\text { relative data, } \\
\text { comparing values, } \\
\text { functions }\end{array}$ & $\begin{array}{l}\text { Working with } \\
\text { diagrams, spatial } \\
\text { imagination, } \\
\text { percentages, relative } \\
\text { and absolute data, } \\
\text { direct proportionality, } \\
\text { comparing values, } \\
\text { comparing areas, } \\
\text { functions }\end{array}$ \\
\hline & Map scale use & $\begin{array}{l}\text { Ratio, scale, length } \\
\text { measurement, units of } \\
\text { length and area }\end{array}$ & $\begin{array}{l}\text { Ratio, scale, length } \\
\text { measurement, units of } \\
\text { length and area }\end{array}$ \\
\hline \multirow[t]{2}{*}{ 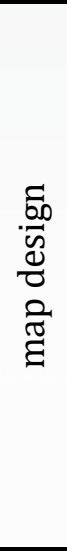 } & $\begin{array}{l}\text { Data collection, } \\
\text { preparation, and } \\
\text { categorization for map } \\
\text { design }\end{array}$ & $\begin{array}{l}\text { Fundamentals of } \\
\text { statistics and working } \\
\text { with data, working } \\
\text { with tables, linear } \\
\text { arrangement, number } \\
\text { sequences, quantitative } \\
\text { sorting, intervals, } \\
\text { relative values, } \\
\text { percentages }\end{array}$ & $\begin{array}{l}\text { Fundamentals of } \\
\text { statistics and working } \\
\text { with data, working } \\
\text { with diagrams, charts } \\
\text { and tables, linear } \\
\text { arrangement, number } \\
\text { sequences, quantitative } \\
\text { sorting, percentages }\end{array}$ \\
\hline & $\begin{array}{l}\text { Drawing elements of } \\
\text { thematic content onto } \\
\text { a prepared map }\end{array}$ & $\begin{array}{l}\text { Spatial imagination, } \\
\text { coordinate grid }\end{array}$ & $\begin{array}{l}\text { Spatial imagination, } \\
\text { coordinate grid, } \\
\text { working with diagrams }\end{array}$ \\
\hline 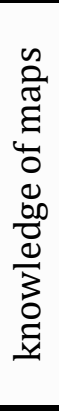 & & $\begin{array}{l}\text { Percentages, ratios, } \\
\text { intervals, relative and } \\
\text { absolute data, } \\
\text { fundamentals of } \\
\text { statistics and working } \\
\text { with data }\end{array}$ & $\begin{array}{l}\text { Working with diagrams } \\
\text { and graphs, } \\
\text { percentages, ratios, } \\
\text { relative x absolute data, } \\
\text { direct proportionality, } \\
\text { functions, comparing } \\
\text { values, fundamentals of } \\
\text { statistics and working } \\
\text { with data }\end{array}$ \\
\hline
\end{tabular}

\section{Chronology of Mathematical and Map Skills in Curricula}

In order to assess the chronological ordering of the development of map skills and necessary mathematical operations, the mathematical operations identified above were grouped into thematic units based on the curricula and textbooks (see the first column of Table 2). Content analysis of both these sources determined when the given mathematical operations are normally developed in students at the lower secondary level (Table 2). 
Table 2

Chronology of mathematical operations needed for the use of thematic maps based on the curricula and textbook content analysis

\begin{tabular}{|c|c|c|}
\hline Mathematical topic & Operations needed for map use & $\begin{array}{l}\text { Developed in school } \\
\text { year }\end{array}$ \\
\hline \multirow{6}{*}{$\begin{array}{l}\text { Numbers and } \\
\text { variables }\end{array}$} & $\begin{array}{l}\text { Comparing values and arrangement, } \\
\text { numerical axis }\end{array}$ & $\mathrm{P}>>\mathrm{LS}>>\mathrm{US}$ \\
\hline & Sets and subsets, intervals & $\mathrm{P}>>6 .+8 .>>\mathrm{US}$ \\
\hline & Fractions & $\mathrm{P}>>7$ \\
\hline & Ratio, scale and cross-multiplication & 7. \\
\hline & $\begin{array}{l}\text { Quotient, percentage and relative } \\
\text { frequency }\end{array}$ & 7. +8 \\
\hline & Squares and roots & 8. + 9. >> US \\
\hline \multirow{6}{*}{$\begin{array}{l}\text { Dependencies, } \\
\text { relationships, and } \\
\text { working with data }\end{array}$} & $\begin{array}{l}\text { Dependencies, relationships and their } \\
\text { properties }\end{array}$ & $\mathrm{P}>>\mathrm{LS}>>\mathrm{US}$ \\
\hline & Cartesian coordinate system & $\mathrm{P}>>7 .+8$ \\
\hline & $\begin{array}{l}\text { Functions (e.g., direct proportionality, } \\
\text { linear functions, root, exponential and } \\
\text { logarithmic functions) }\end{array}$ & 7. + 8. + 9. >> US \\
\hline & Frequency and relative frequency & 7. +9 \\
\hline & $\begin{array}{l}\text { Fundamentals of statistics and } \\
\text { working with data (mean, median, } \\
\text { mode, etc.) }\end{array}$ & 9. $>>$ US \\
\hline & $\begin{array}{l}\text { Working with diagrams, graphs and } \\
\text { tables }\end{array}$ & $\mathrm{P}>>\mathrm{LS}>>\mathrm{US}$ \\
\hline \multirow{9}{*}{$\begin{array}{l}\text { Planar and spatial } \\
\text { geometry }\end{array}$} & $\begin{array}{l}\text { Distinguishing geometric shapes and } \\
\text { patterns }\end{array}$ & $\mathrm{P}$ \\
\hline & Distances and lengths of lines & $P>>7$ \\
\hline & $\begin{array}{l}\text { Planar formations, their properties, } \\
\text { and relative positions }\end{array}$ & $P>>6 .+7 .+8$ \\
\hline & $\begin{array}{l}\text { Spatial formations, their properties, } \\
\text { and relative positions }\end{array}$ & $\mathrm{P}>>\mathrm{LS}>>\mathrm{US}$ \\
\hline & Comparing area sizes & $P>>6 .+7 .+8$. \\
\hline & $\begin{array}{l}\text { Working with ruler, protractor, and } \\
\text { compass }\end{array}$ & $P>>6$ \\
\hline & $\begin{array}{l}\text { Units of length, area and volume, unit } \\
\text { conversions }\end{array}$ & $\mathrm{P}>>6 .+7 .+8 .>>\mathrm{US}$ \\
\hline & Angles and degrees & 6. + 9. >> US \\
\hline & Geometry in space & $\mathrm{P}>>6 .+7 .+9 .>>\mathrm{US}$ \\
\hline \multirow{2}{*}{$\begin{array}{l}\text { Non-standard } \\
\text { application tasks } \\
\text { and problems }\end{array}$} & Spatial imagination & $\mathrm{P}>>6 .+7 .+9 .>>\mathrm{US}$ \\
\hline & Logical thinking & $\mathrm{P}>>\mathrm{LS}>>\mathrm{US}$ \\
\hline
\end{tabular}

Abbreviations: P - primary education, LS - continuously in all grades of lower secondary education, US - upper secondary education; >> - development continued at the next level of education 
Note: Only those years of study in which the given aspects of mathematical literacy are being newly developed are listed. Some of these aspects are then continuously used and practiced during teaching in later years.

The data listed in Table 2 shows that the development of mathematical operations required for working with maps is spread across primary, lower secondary, and upper secondary education. If we compare this data with the traditional arrangement of the geographical curriculum, specifically with regard to the development of map skills, it is clear that block teaching of the thematic unit of cartography in Grade 6 builds upon mathematical operations developed at the primary level of education, but also, in many ways, overtakes the mathematical curriculum. The situation is not improved by the fact that quantitative maps are used very frequently in teaching human geography, which is traditionally planned for Grade 7.

Given the arrangement of the subject matter across the different levels of education, students finishing their lower secondary education should - from the perspective of the mathematical operations they have learned - be capable of working with a thematic map at a standard level, provided that the map uses the most common mapping methods (i.e., choropleth map, diagram map, proportional symbol map, line symbol map, or area-shading map). However, the identified chronology of lower secondary education is problematic, as the teaching of mathematics and geography do not follow up on one another in a logical manner.

\section{Study 2: The Impact of Student Numeracy on Map Skills}

The second study was carried out to investigate the relationship between mathematical literacy and map skills in lower secondary students. As previously mentioned, the analysis is limited to choropleth maps and proportional symbol maps because these are common mapping methods employed to represent quantitative data, which require the users to engage their mathematical skills to a greater extent than when qualitative data are exploited. Thus, these methods were considered more suitable for the stated research aims. Given the specific character of map design skills and that the content of the Framework Education Programme for Elementary Education does not explicitly require students to be able to design thematic maps, this study focuses only on the skills of map reading, analysis, and interpretation.

\section{Methodology}

This study was performed by employing the quantitative research tools of two achievement tests and a questionnaire.

\section{Research Sample}

The research sample, which was chosen using the convenience sampling method but still reflected fundamental between-school variations in Czechia, consisted of 267 students from nine Czech lower secondary schools (four standard elementary schools and five lower grades of eight-year grammar schools). The participants, of which $51 \%$ were boys and $49 \%$ girls, were aged $14-16$ years old. All of them were in the last year of lower secondary education (Grade 9). Moreover, before full 
testing, the achievement tests were pilot tested (with Cronbach's alpha of 0.878) on the sample of 75 students (Grade 9 at lower secondary education) from two elementary schools and two grammar schools.

\section{Materials}

The primary research tools were achievement tests designed to assess work with thematic maps and mathematical literacy. Given that only two thematic map types and three map-related skills (reading, analysis, and interpretation) were involved, a limited selection of mathematical operations was tested. The mathematical areas covered in the developed achievement test included the following items:

- Numbers, numerical operations and variables (numerical comparisons; percentage, quotient, fractions comparison; relative and absolute data; intervals; scale)

- Dependences, relationships, and data handling (function, direct proportion; diagrams)

- Planar and spatial geometry (planar shapes and formations and their mutual positions; distance estimation and measurement; comparison of area surfaces)

- Special application tasks (spatial awareness)

The mathematics test did not involve any map. The items were designed to focus on the above mathematical operations; thus, it required the participants to apply them in a purely mathematical context.

While the mathematical part was newly formed since it is directly based on the results of Study 1, the map-related items were adapted from another study that focused on thematic map use due to its proven validity and reliability for identifying students' level of thematic map skills (Havelková \& Hanus, 2018). The original map use test employed by Havelková and Hanus was reduced to include only choropleth and thematic maps. For each map, the subjects were to decide which of the nine statements provided are true, which are false, and which ones' validity cannot be determined. Three statements required map reading, three focused on map analysis, and the remaining three involved map interpretation. Additionally, the original diagram map used in the achievement test was adjusted to allow for discrimination between absolute and relative data - that is, it was redesigned so that the proportional symbol map represented the absolute values by the size of the diagrams and the relative values by the diagram structure.

The map skill test was comprised of 18 items and the mathematics test consisted of 17 items. In both tests, one point was given for each correctly answered item and zero points for an incorrect answer. The time limit was set at 45 minutes, the standard lesson length. In addition to the tests, each participant completed a questionnaire designed to provide information about the participants' age, gender, liking for geography and mathematics, and their last school report grades in these subjects. 
Hanus, M..; Havelková, L., Švubová, K. (2021). Math-Related Difficulties in Thematic Map Use...

\section{Data Analysis}

To investigate the relationships between the success rate for the mathematical and the map skill tests, as well as between their subparts, the Spearman rank correlation was calculated because the assumption of normal data distribution was not met. Next, multiple linear regression was performed to determine the extent to which the success rate in the map skill test is predicted by the success rate in the mathematics test and by the other independent variables of age, gender, school type, grades, and liking for the geography and mathematics.

\section{Findings}

\section{Overall Results}

On average, the participants were slightly more successful in the map skill test (M $=71.3 \%)$ than in the mathematics test $(\mathrm{M}=68.8 \%)$, with the average success rate in the map skill test varying based on the type of map skill tested (see Table 3). The students performed well in the tasks focused on map reading and, for the most part, in the map analysis tasks. The map interpretation items, on the other hand, were correctly solved by only half of the subjects. Regarding the mapping method employed, the participants were more successful in solving the items with a choropleth map than those with a proportional symbol map. In addition to the type of map skill, the mathematical operations covered by the task represented another variable affecting the student success rate. In general, the least difficulties were posed by the tasks relating to the topics of numbers, variables, and arithmetic operations, which far surpassed the other topics in terms of the success rate. In contrast, the most difficult tasks were the ones that focused on non-standard application exercises and problems, and spatial imagination in particular. Similar difficulties were encountered by the students when solving tasks related to planar and spatial geometry (see Table 3 ).

Table 3

The descriptive statistics for the student success rate in the map skill and mathematics tests and in their subparts

\begin{tabular}{lllll}
\hline & M & SD & Max & Min \\
\hline Map skill test & 71.3 & 15.8 & 100.0 & 22.2 \\
\hline Mathematics test & 68.8 & 22.7 & 100.0 & 7.1 \\
\hline MS-choropleth map & 73.3 & 18.9 & 100.0 & 11.1 \\
\hline MS-proportional symbol map & 69.2 & 18.0 & 100.0 & 22.2 \\
\hline MS-map reading & 85.5 & 15.7 & 100.0 & 33.3 \\
\hline MS-map analysis & 73.1 & 23.7 & 100.0 & 0.0 \\
\hline MS-map interpretation & 55.2 & 22.5 & 100.0 & 0.0 \\
\hline MT-numbers and arithmetic operations & 79.6 & 18.7 & 100.0 & 16.7 \\
\hline MT-dependencies, relations, and working with data & 61.0 & 34.9 & 100.0 & 0.0 \\
\hline MT-planar and spatial geometry & 57.4 & 32.6 & 100.0 & 0.0 \\
\hline MT-non-standard application exercises and problems & 54.5 & 38.0 & 100.0 & 0.0 \\
\hline Abbreviations: M = mean; SD = standard deviation; Max $=$ maximal value; Min $=$ minimal \\
value; MS = map skill test; MT = mathematics test. \\
\hline
\end{tabular}


The relationship between mathematical literacy and map-work skills. The results of the Spearman rank correlation analysis show a significant relationship between the students' success rate in the map skill test and in the mathematics test $(\mathrm{rS}=.60 ; \mathrm{p}<.000)$. The students who were more successful in the mathematics test also achieved better results in the map skill test, and vice versa. The correlation was found to be significant for all the subparts of the mathematics and map skill tests (see Table 4).

Table 4

The results of the Spearman rank correlation analysis for the success rate in the map skill and mathematics tests

\begin{tabular}{lllllll}
\hline & $\mathrm{MS}$ & $\mathrm{MS}_{\mathrm{C}}$ & $\mathrm{MS}_{\mathrm{P}}$ & $\mathrm{MS}_{\mathrm{MR}}$ & $\mathrm{MS}_{\mathrm{MA}}$ & $\mathrm{MS}_{\mathrm{MI}}$ \\
\hline $\mathrm{MT}$ & $.60^{* *}$ & $.48^{* *}$ & $.55^{* *}$ & $.37^{* *}$ & $.50^{* *}$ & $.47^{* *}$ \\
\hline $\mathrm{MT}_{\mathrm{N}}$ & $.61^{* *}$ & $.49^{* *}$ & $.54^{* *}$ & $.35^{* *}$ & $.52^{* *}$ & $.46^{* *}$ \\
\hline $\mathrm{MT}_{\mathrm{D}}$ & $.42^{* *}$ & $.37^{* *}$ & $.35^{* *}$ & $.28^{* *}$ & $.35^{* *}$ & $.34^{* *}$ \\
\hline $\mathrm{MT}_{\mathrm{G}}$ & $.47^{* *}$ & $.32^{* *}$ & $.47^{* *}$ & $.27^{* *}$ & $.38^{* *}$ & $.38^{* *}$ \\
\hline $\mathrm{MT}_{\mathrm{A}}$ & $.33^{* *}$ & $.22^{* *}$ & $.34^{* *}$ & $.22^{* *}$ & $.27^{* *}$ & $.27^{* *}$ \\
\hline
\end{tabular}

Strength of relationship

\begin{tabular}{l} 
very weak \\
weak \\
moderate \\
\hline
\end{tabular}

Note: $* \mathrm{p}<.05^{* *} \mathrm{p}<.001 ;$ abbreviations: $\mathrm{MT}=$ mathematics test; $\mathrm{MS}=$ map skill test; $\mathrm{C}=$ choropleth map; $\mathrm{P}=$ proportional symbol map; $\mathrm{MR}=$ map reading; $\mathrm{MA}=$ map analysis; $\mathrm{MI}=$ map interpretation; $\mathrm{N}=$ numbers and arithmetic operations; $\mathrm{D}=$ dependencies, relations, and working with data; $\mathrm{G}=$ planar and spatial geometry; $\mathrm{A}=$ non-standard application exercises and problems

The strongest positive relationships were identified in the participants' success rate between the numbers, variables and arithmetic operations, and the map skill test, and between the above mathematical topics, proportional symbol map tasks, and the task requiring a thematic map analysis. The correlation value was above .50 for the whole mathematics test and the listed parts of the map skill test - that is, the proportional symbol map and map analysis skill (see Table 4; for data visualization, see Figure 2). 
Hanus, M..; Havelková, L., Švubová, K. (2021). Math-Related Difficulties in Thematic Map Use...
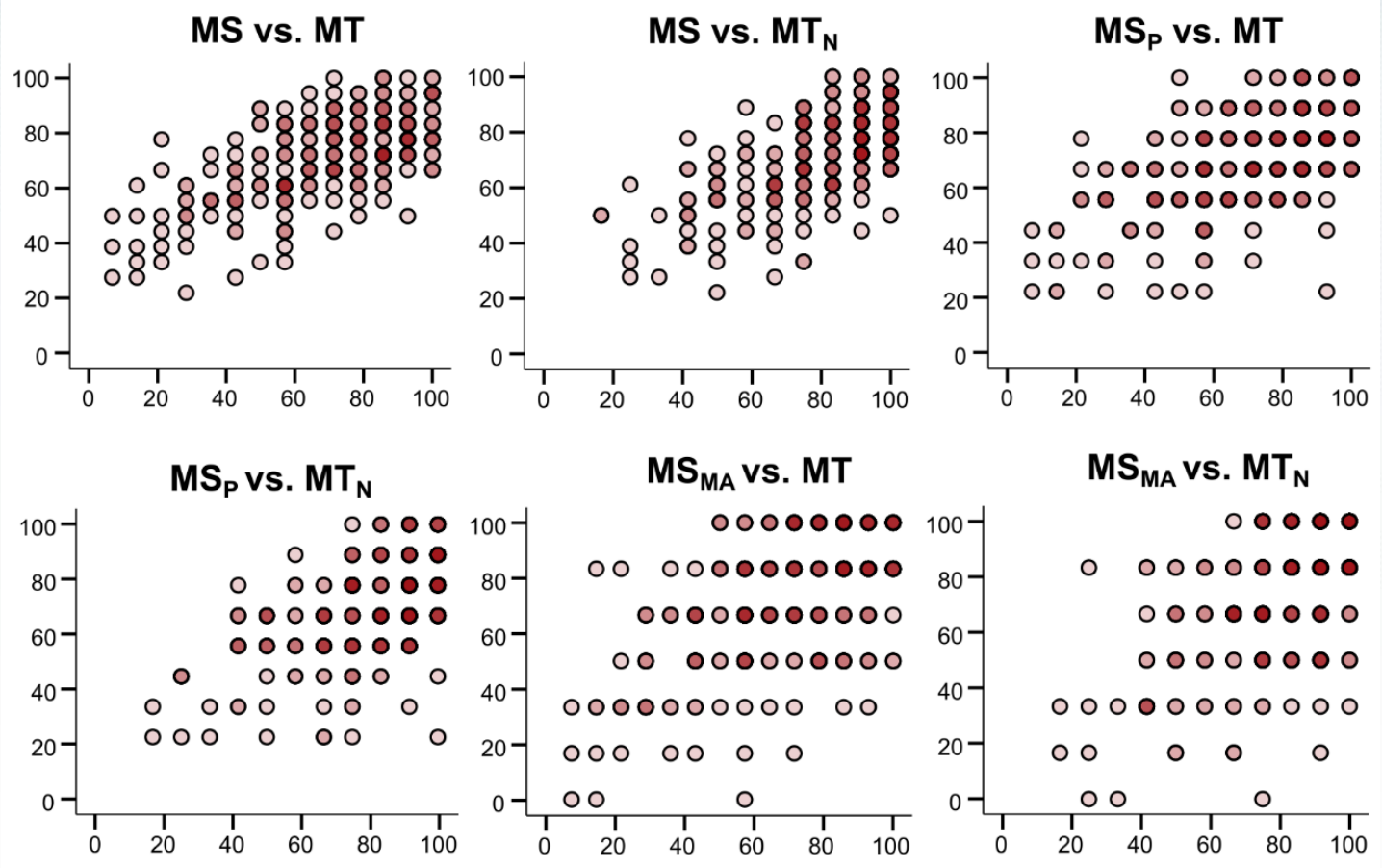

Figure 2. The scatter plots visualizing the data with the highest identified correlation

Note: The $\mathrm{x}$-axis represents the success rate in the mathematics test or its subparts. The yaxis displays the success rate in the map skill test or its subparts. The colour intensity denotes the frequency of overlapping values. For an explanation of the abbreviations used, see the note to Table 4 .

A very weak relationship was identified between the participants' success rate in the tasks requiring spatial imagination (MTA) and all the subparts of the map skill test. In addition, the relationship between the map-related task requiring only thematic map reading and most of the mathematics topics was weak but statistically significant (Table 4).

The significance and strength of the relationship between the participants' success rate in the mathematics and map skill tests could be affected by the investigated independent variables, such as gender and age. Therefore, a multiple linear regression was performed to investigate whether and to what extent the maprelated performance is affected by the other variables.

The students' success rate in the map skill test (MS) was found to be predicted, in addition to the success rate in the mathematics test (MT), by gender (G), age (A), geography and mathematics grades (GG, GM), liking for geography and mathematics (LG, LM), and the school type (ST). The independent variables of gender and liking for geography were not included in the final predictive model, as the correlation between them and the students' success rates in the map skill test was not significant: $r(265)=.06, p=.173 ; r(262)=.04, p=.272$.

For the relationship between the rest of the independent variables and the students' success rates in the map skill test, a significant regression equation was 
found $(F(6,250)=37.79, \mathrm{p}<.000)$ with an $\mathrm{R} 2$ of .48 ; that is, the model explains 48 $\%$ of the variance. The students' predicted success rate in the map skill test equals $36.84+\left(.36^{*} \mathrm{MT}\right)+\left(6.11^{*} \mathrm{ST}\right)-\left(2.24^{*} \mathrm{GM}\right)+\left(.75^{*} \mathrm{~A}\right)+\left(.52^{*} \mathrm{LG}\right)-\left(.38^{*} \mathrm{GG}\right){ }^{1}{ }^{1}$ From the considered independent variables, only the students' success rate in the mathematics test $(\mathrm{p}<.000)$, school type $(\mathrm{p}<.000)$, and mathematics grade $(\mathrm{p}=.048)$ contributed significantly to the model. The participants' success rate in the map skill test increased by $0.36 \%$ for each percentage of the participants' success rate in the mathematics test, and decreased by $2.24 \%$ with each lowering of the mathematics grade by 1 . In addition, the participants attending grammar schools achieved a $6.11 \%$ higher success rate than the participants attending elementary schools. On the other hand, age $(\mathrm{p}=.483)$, geography grade $(\mathrm{p}=.731)$, and liking for mathematics $(p=.665)$ were not significant predictors of the participants' success rate in the map skill test. A comparison of the relative importance of the independent variables in the model revealed the success rate in the mathematics test as the most important predictor (predictor importance: $\mathrm{MT}=.77, \mathrm{ST}=.14, \mathrm{GM}=.09$ ).

The identified math-related difficulties in thematic map use. The results of both the Spearman's correlation analysis and the multiple linear regression show the importance of mathematic literacy for successful thematic map use in the test; thus, it is important to analyse the most difficult tasks in both tests to identify the math-related difficulties in thematic map use.

For two of the three map skill tasks with the average success rate below $40.0 \%$, the participants were expected to indicate that the validity of the given statement cannot be decided based on the provided map. The purpose of these tasks was to find out whether the participants understood the mapping method itself.

In the case of the choropleth map, the participants wrongly assumed that if the relative value of the phenomenon as depicted on the map is high, then its absolute value must be high as well, and vice versa; they had difficulties distinguishing between the relative and absolute data.

With regard to the proportional symbol map, the participants failed to demonstrate understanding that a value pertaining to a particular region is not true for all the cities in the region (i.e., that it is an average value calculated from the subunit values). Here, although the reason could have been that the calculation of an arithmetic mean and other descriptive statistics is only taught in the last year of lower secondary education (see Table 2), the low success rate was most likely caused by the students' lack of awareness of how the data depicted in thematic maps are calculated.

Similar to the choropleth map task discussed above, the third map task with a very low success rate posed a difficulty due to the necessity of distinguishing between relative and absolute values. The participants were to decide in which regions oaks cover most of the area. The task required the students to consider not only the pie chart for oak, which most of the students did, but also the size of the

1 The correlation between the considered independent variables were not significant, very weak, or weak, except for the grades $(\mathrm{r}=.51, \mathrm{p}<.000)$ and mathematics grade and liking for mathematics $(\mathrm{r}=-.51, \mathrm{p}<.000)$. 
diagram that represented the area covered by forests. From the average success rates for the other tasks involving diagrams (both in the map skill and mathematics tests), it is apparent that the participants had no significant difficulties considering the size of the diagram or the size of its slices. This particular map task, however, showed that it was difficult for them to combine the two pieces of information. Another task that was problematic for the same reason (with an average success rate of 53.9\%) required the students to identify the region in which forests cover the largest part of the landmass. When solving this task, it is necessary to compare the size of the forest area represented by the diagram size - that is, to use a legend to identify which value the diagram size represents - with the size of the region in the map.

With regard to the mathematics test, the only task with a success rate below $40.0 \%$ required the students to compare area sizes and use direct proportion; the problematic aspect of the task coincides with that related to the proportional symbol map. The four mathematical tasks with a success rate between 40.0 and $60.0 \%$ were focused on the use of map scale for distance estimation and measuring, spatial imagination, and percentage calculation. Using the map scale did not prove to be excessively difficult in the map skill test because the thematic maps had a graphical scale, not a numerical one. Similarly, the low success rate in a task focused on spatial imagination did not markedly affect the success rate in the map skill test, as the correlation was weak or very weak.

\section{Discussion}

This paper focused on the relationship between mathematical literacy and map use skills, with the aim of identifying and analysing possible math-related difficulties encountered by lower secondary students while using thematic maps. The results of both studies presented support and fundamentally complement the conclusions of previous studies that focused on topographic maps and related mathematical literacy (Anthamatten et al., 2018; Grofelnik \& Pap, 2013; Cheek \& Muir, 1986; Ishikawa, 2016; Liben et al., 2013).

An in-depth analysis of the map-work process showed that mastering various mathematic operations is a prerequisite for the use and design of thematic maps. In other words, a particular level of mathematical literacy needs to be achieved for a map user to be able to perform successful map reading, with more cognitively demanding operations increasing the importance of mathematical literacy. The amount and type of mathematical operations needed is affected not only by the problem solved but by the character of the data and map type as well (Table 1). In general, students with low mathematical literacy will have problems understanding and correctly using thematic maps, which show quantitative data - for example, choropleth maps, diagram and proportional symbol maps, dot maps, dasymetric maps, cartograms, and isopleth maps (Cauvin, Escobar, \& Serradj, 2010; Slocum et al., 2013).

A content analysis of the Czech national and school curricula revealed thematic map use limitations not only in students with low mathematical literacy, but in all those who are in their lower-secondary education (Table 2). Namely, the results of Study 1 showed that, by teaching the basics of cartography to Grade 6 students (age 
12), the geography curriculum is ahead of the mathematics curriculum, which appears to be problematic for several reasons. The first problem is the need to allocate enough of the geography lesson time to fostering students' mathematical literacy, possibly at the expense of other geographical topics. The second problem concerns the higher demands placed on the expertise of the teacher and the increased risk of students' misconceptions. Geography teachers are often not qualified to teach mathematics-related topics (Knecht, Spurná, \& Svobodová, 2020; Svobodová, Spurná, \& Knecht, 2020). As a result, the use of thematic maps in geography lessons - for example, for the purpose of explaining abstract topics such as urbanization, global climate change, and sector structures of the economy, or for solving complex geographic problems - can lead students to form misconceptions about the discussed phenomenon, its spatial distribution, the depicted area, and the mapping method used.

Rasmussen and Winsløw (2013) suggested a possible solution for the lack of synchronicity of mathematics and geography curricula, proposing to fuse maprelated work and mathematics together and thus allowing for map-work skills to develop alongside mathematical literacy. Since the integration of mathematics into geography lessons can be difficult to realize, the two curricula should at least be appropriately coordinated. More specifically, map-work skills should only be developed after a sufficient degree of numeracy is achieved (Cheek \& Muir, 1986). Also, while certain data visualization methods, particularly qualitative ones, can be employed when working with younger students, quantitative mapping methods should be used later on in geography teaching - namely, in the upper grades of lower secondary education (Havelková \& Hanus, 2018). The studies suggest that it is crucial to consider the level of mathematical literacy needed to perform map-related operations in geography lessons. Some map-work skills can already be fostered at the pre-school and primary education levels, when a map can serve as a tool to develop mathematical literacy (Wiegand, 2006). Illustrating the practical use of abstract mathematical operations, maps can facilitate understanding of these operations (Dorn et al., 2005). The use and design of thematic maps can also be beneficial in the teaching of statistics, dependencies, and relations, and in working with data (Rasmussen \& Winsløw, 2013).

The results of the two studies presented in this paper are in line with the findings of earlier studies, highlighting information that should be used to optimize the lower-secondary curricula, particularly map-related ones, at both the national and school levels. The Czech national curriculum is relatively loose, allowing schools to exercise significant freedom in formulating their own curriculum; thus, there exists no formal obstacle to the mathematics and geography curricula being coordinated with each other. The above appeal therefore concerns primarily school-level curriculum leaders who would, nevertheless, certainly welcome complex, systematic support from the national level. In sum, it is advisable that national curriculum designers and experts in geography education together participate in the process of curricula adjustment.

It should be noted that synchronizing the two curricula does not necessarily entail lowering the cognitive demands of map work in schools. In fact, fostering map analysis, interpretation, and design skills helps students develop geographical 
thinking (Geographical Association, 2009; Hanus \& Marada, 2013). Nevertheless, maps for geography lessons must be chosen carefully, considering the phenomenon depicted, the data characteristics, and the cartographic quality of the maps and their appropriateness for education. Clearly, then, developing map work as an essential part of geographic skills is a complex, long-term process that should be well-planned and reflective of the qualified teacher's personal concept of map skills development (Hanus \& Havelková, 2019).

The results of Study 2 explicitly show that the discord between the mathematic and geographic curricula needs to be addressed. Fostering mathematical literacy is highly important because mathematical literacy levels have been found to be positively correlated with thematic map work success rates (this result is in line with Grofelnik \& Pap, 2013; Havelková \& Hanus, 2018; van Dijk et al., 1994). The empirical nature of the present research has made it possible to demonstrate that maps cannot be considered to be a homogeneous source of information, but rather a profoundly variable one, covering various map types (general reference, topographic, thematic) as well as the different mapping methods used in thematic maps (Havelková \& Hanus, 2018). While the studies focusing on topographic maps (Anthamatten et al., 2018; Ishikawa, 2016) have established a relationship between successful topographic map use and spatial orientation, the link between spatial orientation and successful (quantitative) thematic map use has been found to be weak; the correlation was significant but at the lowest level of all the investigated relationships. Likewise, the mathematic operations essential for the use of thematic maps depicting quantitative data are not necessary to navigate topographic maps, and similar differences can be expected with regard to qualitative thematic maps.

Beyond the map type, the map skills to be developed also need to be considered (Havelková \& Hanus, 2019). Besides indicating that the various map-related operations are associated with different cognitive demands, this study has also revealed the different degrees of correlation between map work and mathematical literacy. Predictably, the strongest correlation was found between mathematical literacy and map analysis skills (see also Ishikawa, 2016); nevertheless, certain mathematical literacy is needed in map reading as well. The same holds true for map interpretation; its dependency on numeracy was proven by the present study but not by Ishikawa (2016), which may be related to the fact that Ishikawa (2016) only considered spatial ability with regard to mathematical literacy.

Furthermore, the results of the present study indicate that low success rates in map interpretation tasks are at least partially caused by insufficient mathematical literacy, or by not using them appropriately. An analysis of the most difficult map tasks showed that students had problems differentiating between relative and absolute data and were generally unaware or unable to apply the knowledge of how primary data are modified prior to map design (relativized, averaged, categorized, etc.).

Accordingly, the use of choropleth maps, in which the presented data are related to values other than the depicted territory (e.g., the number of inhabitants), needs to be carefully considered. Teachers should always make sure that their students understand that the spatial distribution of the depicted phenomenon and values are 
influenced by the phenomenon to which they are related. There is a need to specifically include activities that help students distinguish between absolute and relative data - e.g., understanding that the population and the area of Malta are small, but that the population density of Malta is very high.

Additionally, some mathematical operations that were not correctly applied in the map skill test may seem simple to lower secondary students, but results show that this is not the case. Students only learn the individual procedures of problem solving, but they do not sufficiently develop the ability to apply mathematical operations in new, not purely mathematical, situations - which is related to the lack of attention devoted to the situations and contexts component of mathematical literacy in the national curriculum.

Finally, the implications of the Study 1 and Study 2 findings for curriculum leaders and geography teachers should be reflected by the teacher trainers, especially in their pre-service teachers' courses, to prevent the future recurrence of math-related difficulties in map use at lower secondary lessons.

\section{Limitations}

The limitations of the methodology and findings of this research must be considered when interpreting it. First, there are limitations in terms of the curriculum analysis. The national curriculum is a general document that each school can specify, for instance, according to its specific educational conditions or its teachers' personal concepts of teaching. Therefore, the five different school curricula analysed cannot describe the complex curriculum variability that exists. However, most schools follow the traditional scheme of teaching that is sufficiently expressed by the analysed curricula (Janík, Maňák, Knecht, \& Němec, 2010).

Second, the research focused on quantitative thematic maps where the higher need for mathematical literacy was expected. However, only the two most common quantitative maps were considered, and the results could vary in the case of other map types (e.g., cartograms, dot maps, dasymetric maps). Moreover, the research focused only on map use skills; the correlation of map design and level of mathematical literacy should be of interest in future studies.

Third, one should be aware of the limited extent of the research sample and the non-probability of sampling in Study 2 might not represent the results for the whole population of students at the end of their lower secondary studies in Czechia.

Finally, there are limitations related to the statistical analysis in Study 2. Mainly, the identified strength of correlation between the success rates in the mathematics and map skill tests could be positively influenced by the fact that the mathematics test stressed only operations that were considered necessary for the successful use of the maps based on the cognitive walkthrough. Similarly, such a focus could influence the results of the multiple linear regression.

\section{Conclusion}

The math-related difficulties experienced by students can originate from or be influenced by the actual character of the Czech education system, namely, its mathematics and geography curricula. In this context, it is necessary to conduct 
further study on the relationship between mathematical literacy and map skills from the perspective of projected curricula and to broaden the knowledge by analysing other national and school curricula. Similarly, the list of identified mathematical operations needed for the use and design of thematic maps - the choropleth and proportional symbol map in particular - must be discussed widely within the expert community of cartographers, teachers, and curriculum designers, and then improved according to the results of the relevant empirical studies.

It is crucial for geography educators - even at the lower secondary level - to be aware of the mathematical operations needed to fully understand maps and make complex use of them to better understand other geographical issues and further develop geographical thinking. Teachers should also consider poor level of mathematical literacy as one of the possible causes of students' difficulties in map work. Although one could argue that the identified low level of students' map skills is much more a question of good quality geography education, a certain level of students' mathematical literacy could help geography teachers focus on the geographical rather than mathematical aspects of the use of maps and subsequently increase the quality of geography teaching.

Future studies should also pay more attention to the aspects of mathematical literacy that were not exhaustively investigated in this article (e.g., mathematical reasoning), concentrating also on the relationships between the given aspects and the level of students' map skills. More importantly, mathematics literacy and its impact on map-skill level should be tested on younger students who were not formally taught the majority of the fundamental mathematical operations. Moreover, this research should be followed by studies to verify whether - and if so, how - students' early use of (quantitative) thematic maps can lead to a formation or change of their (geographical) misconceptions.

\section{Acknowledgement}

This work was supported by Charles University under Charles University Research Centre program no. UNCE/HUM/024

\section{References}

Anthamatten, P., Bryant, L. M. P., Ferrucci, B. J., Jennings, S., \& Theobald, R. (2018). Giant Maps as Pedagogical Tools for Teaching Geography and Mathematics. Journal of Geography, 117(5), 183-192.

Cheek, H., \& Muir, S. P. (1986). Mathematics and the Map Skill Curriculum. School Science and Mathematics, 86(4), 284-291.

Cauvin, C., Escobar, F., \& Serradj, A. (2010). Thematic Cartography and Transformations. London: ISTE.

Dorn, R. I., Douglass, J., Ekiss, G. O., Trapido-Lurie, B., Comeauz, M., Mings, R., ... Ramakrishna, B. (2005). Learning Geography Promotes Learning Math: Results and Implications of Arizona's GeoMath Grade K-8 Program. Journal of Geography, 104(4), 151-160.

Geographical Association. (2009). Geography for Life, 2nd Edition, National Geography Standards. Washington: Geographical Association. 
Grofelnik, H., \& Pap, I. (2013). Mastery of Long-Term Cartographic Knowledge and Skills of New Entry Secondary Level Pupils. Kartografija i Geoinformacije (Cartography and Geoinformation), 12(19), 86-102.

Ishikawa, T. (2016). Spatial Thinking in Geographic Information Science: Students' Geospatial Conceptions, Map-Based Reasoning, and Spatial Visualization Ability. Annals of the American Association of Geographers, 106(1), 76-95.

Hanus, M., \& Havelková, L. (2019). Teachers' concepts of map-skill development. Journal of Geography, 118(3), 101-116.

Hanus, M., \& Marada, M. (2013). Mapové dovednosti v českých a zahraničních kurikulárních dokumentech: Srovnávací studie. Geografie, 118(2), 158-178.

Hanus, M., \& Marada, M. (2014). Mapové dovednosti: Vymezení a výzkum. Geografie, 119(4), 406-422.

Havelková, L., \& Hanus, M. (2018). The Impact of the Map Type on the Level of Student Map Skills. Cartographica, 53(3), 149-170.

Havelková, L., \& Hanus, M. (2019). Map skills in education: A systematic review of terminology, methodology, and influencing factors. Review of International Geographical Education Online, 9(2), 361-401.

Jablonka, E. (2003). Mathematical Literacy. In A. J. Bishop, M. A. Clements, C. Keitel, J. Kilpatrick, \& F. K. S. Leung (Eds.), Second International Handbook of Mathematics Education (pp. 75-102). Dordrecht: Springer Netherlands.

Jadallah, M., Hund, A. M., Thayn, J., Studebaker, J. G., Roman, Z. J., \& Kirby, E. (2017). Integrating Geospatial Technologies in Fifth-Grade Curriculum: Impact on Spatial Ability and Map-Analysis Skills. Journal of Geography, 116(4), 139-151.

Janík, T., Maňák, J., Knecht, P., \& Němec, J. (2010). Proměny kurikula současné české školy: vize a realita. Obis scholae. 4(3), 9-35.

Knecht, P., Spurná, M., \& Svobodová, H. (2020). Czech secondary pre-service teachers' conceptions of geography. Journal of Geography in Higher Education, 44(3), 458-473.

Korycka-Skorupa, J., \& Gołębiowska, I. M. (2020). Numbers on Thematic Maps: Helpful Simplicity or Too Raw to Be Useful for Map Reading? ISPRS International Journal of Geo-Information, 9(7), 1-24.

Kwan, T. Y. (1994). Teachers' perceptual understanding of mapwork and their styles of mapwork teaching at forms 1-3 levels in Hong Kong. Asian Geographer, 13(2), 75-94.

LaSpina, J. A. (1998). The Visual Turn and the Transformation of the Textbook. Mahwah, NJ: Routledge.

Liben, L. S., Myers, L. J., Christensen, A. E., \& Bower, C. A. (2013). Environmental-Scale Map Use in Middle Childhood: Links to Spatial Skills, Strategies, and Gender. Child Development, 84(6), 2047-2063.

OECD. (2003). The PISA 2003 Assessment Framework - Mathematics, Reading, Science and Problem Solving Knowledge and Skills. Paris: Organization for Economic Cooperation and Dvelopment.

Polson, P. G., Lewis, C., Rieman, J., \& Wharton, C. (1992). Cognitive walkthroughs: A method for theory-based evaluation of user interfaces. International Journal of Man-Machine Studies, 36(5), 741-773.

Rasmussen, K., \& Winsløw, C. (2013). Didactic codetermination in the creation of an integrated math and science teacher education: The case of mathematics and 
geography. Proceedings of the 8th Congress of the European Society for Research in Mathematics Education, 3206-3215. Behiye Ubuz, Çiğdem Haser, Maria Alessandra Mariotti (Eds.).

Rendl, M., Vondrová, N., Hříbková, L., Jirotková, D., Kloboučková, J., Kvasz, L., ... Žalská, J. (2013). Kritická místa matematiky na základní škole očima učitelů. Praha: Univerzita Karlova v Praze, Pedagogická fakulta.

Research Institute of Education. (2007). Framework Education Programme for Elementary Education. Praha: Research Institute of Education. Retrieved from http://www.vuppraha.rvp.cz/wp-content/uploads/2009/12/RVP_ZV_EN_final.pdf

Research Institute of Education. (2011). Literacy in Education. Praha: Research Institute of Education.

Schaab, G., Adams, S., \& Coetzee, S. (2020). Conveying map finesse: Thematic map making essentials for today's university students. Journal of Geography in Higher Education, $0(0), 1-27$.

Slocum, T. A., McMaster, R. B., Kessler, F. C., \& Howard, H. H. (2013). Thematic Cartography and Geovisualization. Harlow: Pearson Education Limited.

Svobodová, H., Spurná, M., \& Knecht, P. (2020). Pojetí geografie a geografického vzdělávání u studentů učitelství v Česku. Geografie, 124(4), 501-526.

Uttal, D. H. (2000). Seeing the Big Picture: Map Use and the Development of Spatial Cognition. Developmental Science, 3(3), 247-264.

van Dijk, H., van der Schee, J., Trimp, H., \& van der Zijpp, T. (1994). Map skills and geographical knowledge. International Research in Geographical and Environmental Education, 3(1), 68-80.

Whittle, M. P. (2007). Meaningful Maths: Teaching Map Skills. Australian Primary Mathematics Classroom, 12(3), 30-32.

Wiegand, P. (2006). Learning and Teaching with Maps. New York: Routledge.

\section{Biographical Statements}

Martin HANUS is assistant professor at the Centre for Geographical and Environmental Education, Department of Social Geography and Regional Development, Faculty of Science, Charles University, Prague. His research interests are mainly within map skills and related aspects of geography education (including curriculum, teaching, strategies, and educational outcomes). Moreover, he focuses on general research in geography education, including topics such as the world-mindedness of young people, geography skills, geocapabilities, and geographical disparities..

Lenka HAVELKOVÁ is assistant professor at the Centre for Geographical and Environmental Education, Department of Social Geography and Regional Development, Faculty of Science, Charles University, Prague. Her research activities are centered around educational cartography and map skills. She has developed a particular research interest in students' strategies for solving problem tasks with maps and students' misconceptions that influence their understanding and use of maps.

Kateřina ŠVUBOVÁ is an in-service teacher in geography and mathematics at the lower and upper tiers of secondary education. She is interested in possible ways of integrating both of these fields within general education. 